\title{
Quality of life patients on hemodialysis in Kerala
}

Mathews $\mathrm{TG}^{1 *}$, Mathew $\mathrm{E}^{2}$

\section{*Corresponding author:}

${ }^{1}$ Dr Tessy Grace Mathews M.Phil, Ph.D. Clinical psychologist, Research Scholar, SBES, M.G. University, Kerala, India

Email: tessygrace544@yahoo.co.in ORCID

${ }^{2}$ Asst. Prof, Dept. of Community Medicine, Pushpagiri Institute of Medical Sciences \& Research Centre

\section{Information about the article:}

Received: Jan. 17, 2019

Accepted: Feb. 20, 2019

Published online: Dec. 27, 2019

Publisher

Nepal Health Research Society, Bahundhara -6, Gokarnesowor Municipality, Kathmandu, Nepal eISSN 2382-5545, ISSN 2676-1343 (Print)

(c) The Author(s). 2019

Content licensing: CC BY 4.0

\begin{abstract}
Background

End Stage Renal Disease (ESRD) is on the rise in the recent years which carries with it emotional, physical, psychological, social, and existential burdens that impact their Quality of life (QOL). The QOL describes life satisfaction and life concerns and are affected by health and illness. Maintenance of QOL with the effects of chronic illness is a challenging, multifaceted, complex endeavour for patients, their families and the health professionals. Objective: To assess the kidney disease related quality of life in patients with ESRD, its association with selected demographic, socio economic, disease and treatment related characteristics of ESRD patients.
\end{abstract}

\section{Materials and methods}

Descriptive survey was conducted on 112 participants diagnosed with ESRD and on hemodialysis at least for a minimum duration of 1 month, were recruited from both government and private hospitals through purposive sampling as per the inclusion and exclusion criteria. The Kidney Disease Quality of Life (KDQOLTM-36) and Personal Data Sheet were used to assess the QOL and to obtain information as per the objectives. Descriptive analysis and Chi square test were used to analyze the data.

\section{Results}

Majority of the ESRD subjects had poor quality of life in all the domains, higher proportion being in the burden of illness (71.4\%) and effects of illness (68.8\%) domains. There was a significant association between the burden of illness and marital status $(\mathrm{p}=.01)$, type of bystander $(\mathrm{p}=.01)$;symptom and type of bystander( $\mathrm{p}=.03)$

\section{Conclusion}

Majority of the ESRD patients had low KDQOL scores indicating poor quality of life in all the domains requiring intervention. This emphasizes the need to identify as well as manage QOL among them and develop appropriate intervention

Key words

End stage renal disease, Kidney Disease Quality of Life 